\title{
An exploratory factor analysis into the applicability of the Spirituality Care-Giving Scale, the Spirituality and Spiritual Care Rating Scale and the Spirituality in Occupational Therapy Scale to the South African context
}

\author{
Thuli G Mthembu, BSc OT (UWC), MPH (UWC) \\ $\mathrm{PhD}$ candidate, Department of Occupational Therapy, University of the Western Cape
}

\author{
Nicolette V Roman, MACFS, PhD (UWC) \\ Department of Social Work, University of the Western Cape
}

Lisa Wegner, BSc OT (Wits), MSc OT (UCT), PhD (UCT)

Department of Occupational Therapy, University of the Western Cape

Spirituality and spiritual care are both considered as important elements of health sciences education; however, limited research has been conducted with occupational therapy students using spirituality scales. Therefore, this study assessed the internal consistency component of reliability and carried out factor analyses of three spirituality scales which examined the perceptions and attitudes of South African undergraduate occupational therapy students regarding spirituality and spiritual care. This study used a cross-sectional survey design using convenience sampling to recruit 100 participants. The internal consistency of the instruments evaluated showed satisfactory reliability: i.e. the Spiritual Care-Giving Scale $(\alpha=0.946)$, the Spirituality and Spiritual Care Rating Scale $(\alpha=0.764)$ and the Spirituality in Occupational Therapy scale $(\alpha=0.868)$. The Kaiser-Meyer-Olkin measure of Sampling Adequacy values was 0.862 , 0.883 , and 0.868 respectively, indicating the appropriateness of the factor analysis. Factor analysis from varimax rotated results was also performed to identify the patterns of spirituality and spiritual care within the instruments. The total variances of the instruments were acceptable at 59.1, 67.6 and 69.8\% respectively. An implication of these findings is the possibility that exposing occupational therapy students to spirituality and spiritual care could be useful for them to gain insight into and be sensitive to the clients' spiritual needs. Further research should be undertaken in other institutions of higher learning that offer occupational therapy programmes.

Keywords: Exploratory factor analysis, reliability, spirituality, spiritual care, occupational therapy

\section{INTRODUCTION}

Factor analysis forms part of the statistical methods which play an important role in reducing data through assessing and identifying simple patterns of relationships between variables within a measurement $^{1,2,3}$. According to Kayastha et al. ${ }^{2}$ and Venkaiah, et al. ${ }^{3}$, factor analysis attempts to ascertain whether observed variables can be explained in a smaller proportion of variables clustered in a set of measurements, which are then labelled as factors. Beavers et al.' recommended that for the purpose of factor analysis - researchers should allow for a sufficient sample size, consider the difference between component analysis and common factor analysis as well as rotation of initial factor pattern matrix. Therefore, the role of factor analysis can be better understood when considering the need for spirituality and its importance and relevance to occupational therapy.

\section{Spirituality in occupational therapy}

Occupational therapy is a profession that considers holistic and patient-centred approaches in order to provide effective intervention to clients ${ }^{4}$. For instance, the holistic approach supports the occupational therapists' view of clients' needs as related to the physical, emotional, mental and spiritual spheres. However, most of the time the spiritual element of the holistic approach is neglected and not considered part of holism. Puchalski et al. ${ }^{5: 646}$ defined spirituality as "a dynamic and intrinsic aspect of humanity through which persons seek ultimate meaning, purpose, and transcendence, and experience relationship to self, family, others, community, society, nature, and the significant or sacred. Spirituality is expressed through beliefs, values, traditions, and practices". Spirituality is thus an important aspect of holistic and patient-centred approaches in occupational therapy. This is also highlighted in the American Occupational Therapy Association's Occupational Therapy Practice Framework [OTPF] ${ }^{6}$. The framework presents spirituality as one of three client factors together with values and beliefs, as well as body functions and body structures that contribute to the client's occupational performance.

Despite the fact that the OTPF acknowledges spirituality, there is no emphasis on how occupational therapy education should prepare students regarding spirituality. Several studies have highlighted that spirituality and spiritual care both play a significant role in clients' occupational performance and engagement, health, quality of life and well-being ${ }^{7-9}$. Numerous studies conducted with Canadian and American occupational therapists identified difficulties in addressing spirituality in occupational therapy practice ${ }^{10,11}$. These difficulties included procedural issues (i.e. whether to discuss spirituality, assessment, and application to treatment), guidance needed, and third party players not reimbursing for service. Some of the difficulties reported in those studies were found to be related to a lack of educational guidelines on how to incorporate spirituality into occupational therapy education and practice. This is consistent with Capeheart-Meningall' ${ }^{12}$ who points out that there are challenges 
for universities to educate students holistically and indicated that spirituality is one of the most sensitive and potentially controversial topics. However, the author added that there are various outcomes related to spirituality including "empathy, understanding and caring for others, importance of reducing pain and suffering in the world, feeling a strong connection to all humanity, (and a) compassionate self-concept"|2:33. Therefore, numerous studies in occupational therapy suggested that both students and clinicians should be provided with an opportunity to explore and experience their own spirituality as part of self-awareness and self-reflection in the occupational therapy education and practice p.13,14 $^{5}$

South Africa is a spiritually diversified country, 7,15 . Therefore, health care professionals need to be aware of, sensitive to and competent in understanding their clients'diverse spiritual needs. There is, however, limited knowledge and little research has been conducted on the instruments used to measure occupational therapy students' perceptions and attitudes regarding spirituality and spiritual care in occupational therapy in a South African context. Accordingly, the results of this study can contribute to the development of guidelines to integrate spirituality into occupational therapy education. Therefore, this study aimed to assess the internal consistency component of reliability of three spirituality scales used for spirituality and spiritual care. It also carried out a factor analysis of the perceptions and attitudes of undergraduate occupational therapy students regarding spirituality and spiritual care.

\section{LITERATURE REVIEW}

Spirituality and spiritual care are both an important part of teaching and learning in health sciences education. It has therefore become, and will continue to be, extremely important to understand spirituality and cultural diversity as well as to measure spirituality and spiritual care in theory and education.

\section{Understanding of spirituality and cultural diversity in education}

Spirituality and cultural diversity are both increasingly recognised as significant elements of health sciences education in order to provide effective patient care ${ }^{16-19}$. Cultural diversity is defined as a form of appreciating the differences among people including gender, sex, age, ethnicity, sexual orientation and social status. Accordingly, it was suggested that students should become adept and aware of patients' spirituality and culture while conducting assessments ${ }^{7}$. This is consistent with Hemphill's ${ }^{16: 12}$ assertions that "spiritual issues can be approached as an aspect of diversity and treated with the same respect as any personal issue". However, previous studies report that the inclusion of spiritual content into education is very limited in the institutions of higher education, which challenges acknowledgement of diversity and students' abilities to make internal connections ${ }^{18,19}$. Thus, Tisdell in Dalton ${ }^{19}$ suggest that educational institutions should acknowledge students' cognitive, affective, sociocultural and spiritual aspects in order to promote and facilitate transformation in a pluralistic society. This has resulted in a burgeoning need for integration of spirituality into occupational therapy education at all levels so that educational programmes will equip students with knowledge about society's spiritual needs. There are, however, no reliable and valid instruments to measure these concepts among occupational therapy students. Thus, three research instruments were reviewed regarding measuring spirituality and spiritual care including the Spiritual CareGiving Scale (SCGS) ${ }^{20}$, the Spirituality and Spiritual Care Rating Scale $(\mathrm{SSCRS})^{21}$ and the Spirituality in Occupational Therapy Scale (SOTS) ${ }^{22}$.

\section{Spiritual Care-Giving Scale (SCGS)}

Tiew and Creedy $^{20}$ conducted a quantitative study with 745 students aimed at developing and testing the Spirituality Care-Giving Scale (SCGS) that measured student nurses' perceptions towards spirituality and spiritual care in Singapore. The SCGS was found to be valid and reliable with a Cronbach's alpha value of 0.96 . Additionally, the findings from the SCGS might be used in preparation for continuous professional development to facilitate spiritual care ${ }^{20}$.
Furthermore, the SCGS can be used as a spiritual assessment prior introducing the topic of spirituality to obtain a baseline of students' perceptions and attitudes regarding spirituality in institutions of higher education to inform integration of spirituality in education. The SCGS includes five factors: (I) Attributes for Spiritual Care, (2) Spirituality Perspective, (3) Defining Spiritual Care, (4) Attitudes to Spiritual Care and (5) Spiritual Care Values.

\section{Spirituality and Spiritual Care Rating Scale (SSCRS)} McSherry, Draper and Kendrick ${ }^{21}$ conducted a quantitative descriptive survey with 559 nurses in England using the SSCRS, to discover and explore nurses' understanding of, and attitudes towards, the concepts of spirituality and spiritual care. The findings of the SS$\mathrm{CRS}^{21}$ reported a Cronbach's alpha of 0.64 in this study. Additionally, the SSCRS may be used in the area of spiritual assessment for both education and practice in order to provide researchers with a framework to gain insight into spirituality and spiritual care. The SSCRS was designed specifically to explore nurses' beliefs and values and has four factors: (I) Spirituality; (2) Spiritual Care; (3) Religiosity; and (4) Personalised Care.

\section{Spirituality in Occupational Therapy Scale (SOTS)}

Morris et al.'s22 study with 97 occupational therapists in the United States, described therapists'views related to spirituality in education, scope of practice, and knowledge of the newest version of the OTPF. The findings of this study indicated that the occupational therapists agreed that spirituality is an important component of human experience. In relation to SOTS, there was no report about the reliability and validity tests of the scale. The SOTS is a 20-item, 5 -point, Likert-type questionnaire ${ }^{22}$ and is designed to examine occupational therapists' self-reported perceptions regarding: (I) Inclusion of spirituality in the OTPF, (2) Spirituality in practice, (3) Need for future educational opportunities and training to address spirituality, and (4) Clients' spiritual needs.

\section{METHODS}

A quantitative, descriptive cross-sectional design was used for this study. Convenience sampling was used to recruit 198 potential participants for the study of which only 103 participants from all years responded to the online questionnaire. The questionnaire was distributed to all participants via email in a form of a link developed using Google Forms and participants were consistently reminded about the study via email. However, three participants were excluded due to missing data on their responses. Therefore, the final sample comprised 100 undergraduate occupational therapy students. The participants managed to complete the online questionnaire in the computer laboratory within 30 minutes. The participants' responses were automatically entered onto a Google spreadsheet.

\section{Measuring instruments}

In this study, three of the research measurements were used for data collection process: the Spirituality Care-Giving Scale (SCGS) ${ }^{20}$, the Spirituality and Spiritual Care Rating Scale (SSCRS) ${ }^{21}$ as well as the Spirituality in Occupational Therapy Scale (SOTS) ${ }^{22}$.

\section{Spiritual Care-Giving Scale (SCGS)}

The SCGS is a 35-item scale comprising five factors with a 6-point Likert scale, which was developed and tested to be valid and reliable with a Cronbach's alpha value of $0.96^{20}$. Permission to use the SCGS questionnaire was obtained from Prof. L.H.Tiew.

\section{Spirituality and Spiritual Care Rating Scale (SSCRS)}

The SSCRS instrument is a I7-item, 5-point, Likert scale ${ }^{21}$ used to measure spirituality and spiritual care of nurses and students and was shown to have a Cronbach's alpha value of $0.64^{21}$. Permission to use the SSCRS questionnaire was obtained from Prof. W. McSherry.

\section{Spirituality in Occupational Therapy Scale (SOTS)}

The SOTS is a 20-item, 5-point, Likert-type Scale ${ }^{22}$ used to measure spirituality in occupational therapy. The SOTS was designed specifi- 
cally to examine occupational therapists' self-reported perceptions regarding spirituality. No reliability and validity studies have been reported ${ }^{22}$. Permission to use the SOTS questionnaire was obtained from Dr. D.N. Morris.

\section{Data Analysis}

Data were automatically tabulated in an Excel spreadsheet and imported into SPSS 22 for statistical analysis (SPSS, Inc., 20I5). It is important that research instruments undergo psychometric testing for assessing the applicability and reliability of the scales ${ }^{23,24}$. Hence, this study used the Cronbach's coefficient alpha ${ }^{23}$ to analyse the internal consistency for each of the three scales.

This study also carried out a factor analysis of the perceptions and attitudes of undergraduate occupational therapy students regarding spirituality and spiritual care using Principal Component Analysis (PCA)'. In addition, the PCA was computed to extract factors and reduce the number of items to a smaller number to represent components. An orthogonal rotation' 'was also computed using varimax to generate factor scores. Eigenvalues were used to retain all factors greater than one and factor loadings greater than 0.40 . A scree test was used in conjunction with the eigenvalues to determine and control the number of factors to be retained after rotation ${ }^{25}$. There are two assumptions related to exploratory factor analysis: I) the determinant should be more than $.0000 \mathrm{I}$ in order to perform exploratory factor analysis, and 2) the Kaiser-Meyer-Olkin measure of Sampling Adequacy (KMO) value should be greater than 0.70 which indicates that sample size is adequate for factor analysis ${ }^{25}$.

Regarding the interpretation of the KMO values in a study', it was suggested that researchers use the following guideline: I) A $\mathrm{KMO}$ value range between 0.90 and $\mathrm{I} .00$ is considered as a degree of common variance of marvellous; 2) A KMO value range between 0.80 and 0.89 is considered meritorious; 3 ) A KMO value range between 0.70 and 0.79 is considered middling; 4) A KOM value range between 0.60 and 0.69 is mediocre; 5) A KMO value range between 0.50 to 0.59 is miserable and 6) $\mathrm{KMO}$ value between 0.00 and 0.49 means that factor analysis cannot be calculated.

Bartlett's test of sphericity was computed to test the correlations using chi-square and it was accepted at a statistically significant level of $\mathrm{p}<0.05$.

\section{Ethics}

This study was approved by the Research Ethics Committee of the University of the Western Cape (ethical clearance registration: 14/4/I8). Permission to conduct the study was granted by the Head of the Occupational Therapy Department. The participants
Table I: Demographic characteristics of the sample

\begin{tabular}{|c|c|c|c|}
\hline Students Profile & & Frequency & Percentage \\
\hline \multirow[t]{2}{*}{ Gender } & Female & 88 & $88 \%$ \\
\hline & Male & 12 & $12 \%$ \\
\hline \multirow[t]{2}{*}{ Age } & $18-23$ & 88 & $88 \%$ \\
\hline & $24-33$ & 12 & $12 \%$ \\
\hline \multirow[t]{4}{*}{ Race } & African & 23 & $23 \%$ \\
\hline & White & 30 & $30 \%$ \\
\hline & Coloured & 42 & $42 \%$ \\
\hline & Indian & 5 & $5 \%$ \\
\hline \multirow[t]{4}{*}{ Study year } & First year & 11 & $11 \%$ \\
\hline & Second year & 38 & $38 \%$ \\
\hline & Third year & 22 & $22 \%$ \\
\hline & Fourth year & 29 & $29 \%$ \\
\hline \multirow[t]{2}{*}{ Considers self } & Religious & 40 & $40.6 \%$ \\
\hline & Spiritual & 60 & $59.4 \%$ \\
\hline \multirow[t]{6}{*}{ Religious activities } & $\begin{array}{l}\text { More than once } \\
\text { a week }\end{array}$ & 27 & $27 \%$ \\
\hline & Once a week & 23 & $23 \%$ \\
\hline & Once fortnight & 3 & $3 \%$ \\
\hline & Once a month & 6 & $6 \%$ \\
\hline & Occasionally & 34 & $34 \%$ \\
\hline & Never & 7 & $7 \%$ \\
\hline
\end{tabular}

consented to be part of the study and confidentiality was adhered to by using unique identity numbers to maintain anonymity.

\section{RESULTS}

\section{Characteristics of participants}

A total of 103 questionnaires were included in the data analysis; however, three of the 103 were discarded due to incompleteness leaving a total of 100 participants. The participants were predominantly females who accounted for $86 \%(n=89)$ and male $12 \%$ $(n=12)$. The respondents' ages ranged from 18 to 33 years, with a mean of $21.5 \pm 2.09$ years. See Table $I$.

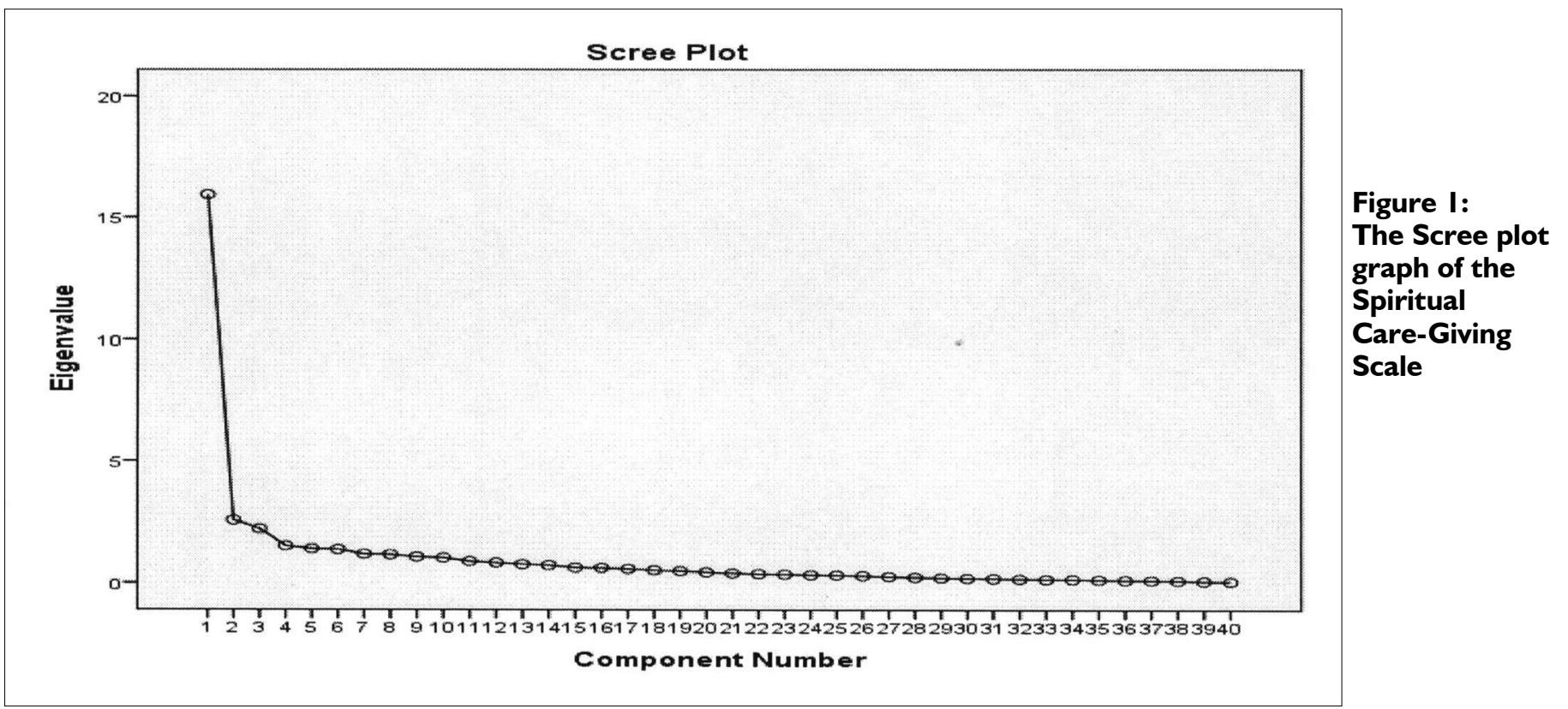




\section{Internal consistency reliability of SCGS}

Overall the internal reliability of the SCGS was $\alpha=0.946$. Therefore, the Cronbach alpha reliability coefficients were calculated for factors of SCGS. The reliabilities ranged from $\alpha=0.155$ to $\alpha=0.934$. Additionally, Factor I (Attributes of spiritual care) of the SCGS had a good reliability of $\alpha=0.934$, and Factor 5 (Spiritual Care Values) with $\alpha=0$. I55. The SCGS showed satisfactory internal consistency reliability.

\section{Exploratory Factor Analysis: SCGS}

The determinant value of the SCGS was 2.916, which indicated that the scale was worthy for the exploratory factor analysis and the KMO of the SCGS was .862within the range of 0.8 and 0.9 . Therefore, the Barlett's test of 2504.556 indicated that the variables of the SCGS were correlated with a statistical significance of a $p$-value of $<.000 \mathrm{I}$. A scree plot of the eigenvalues indicated that five factors could be extracted from the data of SCGS (Figure $I$ on page 76). The PCA revealed that the five factors had an eigenvalue higher than one (Table II). The factor analysis from varimax rotated test indicated that the variances of the factors were $21.7,16.2$, $9.7,5.7$, and $5.5 \%$ respectively. In total, the five-factor solution explained $59.1 \%$ of shared variance.

\section{Table II: Principal components and associate variable}

\begin{tabular}{|c|c|c|c|}
\hline Factor & No & Statement & $\begin{array}{l}\text { Factor } \\
\text { Loading }\end{array}$ \\
\hline \multirow{19}{*}{$\begin{array}{l}\text { Attributes for } \\
\text { Spiritual Care }\end{array}$} & 18 & Occupational therapists provide spiritual care by respecting the religious and cultural beliefs of patients. & 0.763 \\
\hline & 26 & Occupational therapists provide spiritual care by respecting the dignity of patients. & 0.733 \\
\hline & 27 & Spiritual care should take into account of what patients think about spirituality. & 0.727 \\
\hline & 13 & Occupational therapy, when performed well, is itself, spiritual care. & 0.714 \\
\hline & 36 & Spirituality is influenced by individual's life experiences. & 0.655 \\
\hline & 28 & Occupational therapists who are spiritually aware are more likely to provide spiritual care. & 0.654 \\
\hline & 39 & A trusting Occupational therapist -patient relationship is needed to provide spiritual care. & 0.652 \\
\hline & 32 & Spiritual care should be positively reinforced in occupational therapy practice. & 0.635 \\
\hline & 16 & Sensitivity and intuition help the occupational therapist to provide spiritual care. & 0.632 \\
\hline & 17 & Being with a patient is a form of spiritual care. & 0.611 \\
\hline & 19 & Occupational therapists provide spiritual care by giving patients time to discuss and explore their fears, anxieties and troubles. & 0.574 \\
\hline & 29 & Spiritual care requires awareness of one's spirituality. & 0.570 \\
\hline & 11 & Spiritual care is an integral component of holistic occupational therapy. & 0.570 \\
\hline & 31 & Spiritual care should be instilled throughout the occupational therapy education programme. & 0.562 \\
\hline & 38 & Spiritual care requires the occupational therapist to be empathetic towards the patient. & 0.551 \\
\hline & 15 & Spiritual care is respecting a patient's religious or personal beliefs. & 0.550 \\
\hline & 14 & Spiritual care is a process and not a one-time event or activity. & 0.504 \\
\hline & 33 & The ability to provide spiritual care develops through experience. & 0.502 \\
\hline & 40 & A team approach is important for spiritual care. & 0.496 \\
\hline \multirow{10}{*}{$\begin{array}{l}\text { Spirituality } \\
\text { Perspective }\end{array}$} & 9 & Without spirituality, a person is not considered whole. & 0.738 \\
\hline & 3 & Spirituality is part of a unifying force which enables individuals to be at peace. & 0.691 \\
\hline & 7 & Spiritual well-being is important for one's emotional well-being. & 0.689 \\
\hline & 21 & Spiritual care enables the patient to find meaning and purpose in their illness. & 0.677 \\
\hline & 2 & Spirituality is an important aspect of human beings. & 0.657 \\
\hline & 10 & Spiritual needs are met by connecting oneself with other people, higher power or nature. & 0.624 \\
\hline & 12 & Spiritual care is more than religious care. & 0.599 \\
\hline & 8 & Spirituality drives individuals to search for answers about meaning and purpose in life. & 0.588 \\
\hline & 22 & Spiritual care includes support to help patients observe their religious beliefs. & 0.573 \\
\hline & 37 & Spirituality helps when facing life's difficulties and problems. & 0.532 \\
\hline \multirow{4}{*}{$\begin{array}{l}\text { Defining } \\
\text { Spiritual Care }\end{array}$} & 4 & Spirituality is an expression of one's inner feelings that affect behaviour. & 0.714 \\
\hline & 5 & Spirituality is part of our inner being. & 0.700 \\
\hline & 6 & Spirituality is about finding meaning in the good and bad events of life. & 0.629 \\
\hline & 35 & Spiritual care is important because it gives patient hope. & 0.566 \\
\hline \multirow{2}{*}{$\begin{array}{l}\text { Attitudes to } \\
\text { Spiritual Care }\end{array}$} & 23 & Spiritual care is best provided by professional, trained counsellors or spiritual / religious leaders. & 0.749 \\
\hline & 20 & Spiritual care includes visits by the hospital Chaplain or the patient's own religious leader. & 0.706 \\
\hline \multirow{4}{*}{$\begin{array}{l}\text { Spiritual Care } \\
\text { Values }\end{array}$} & 30 & Spiritual care is not the occupational therapist's responsibility. & -0.710 \\
\hline & 25 & I do not believe in spiritual care. & -0.570 \\
\hline & 24 & I am comfortable providing spiritual care to patients. & 0.489 \\
\hline & 34 & Patients must be aware of their own spirituality before an occupational therapist can provide spiritual care. & -0.462 \\
\hline
\end{tabular}




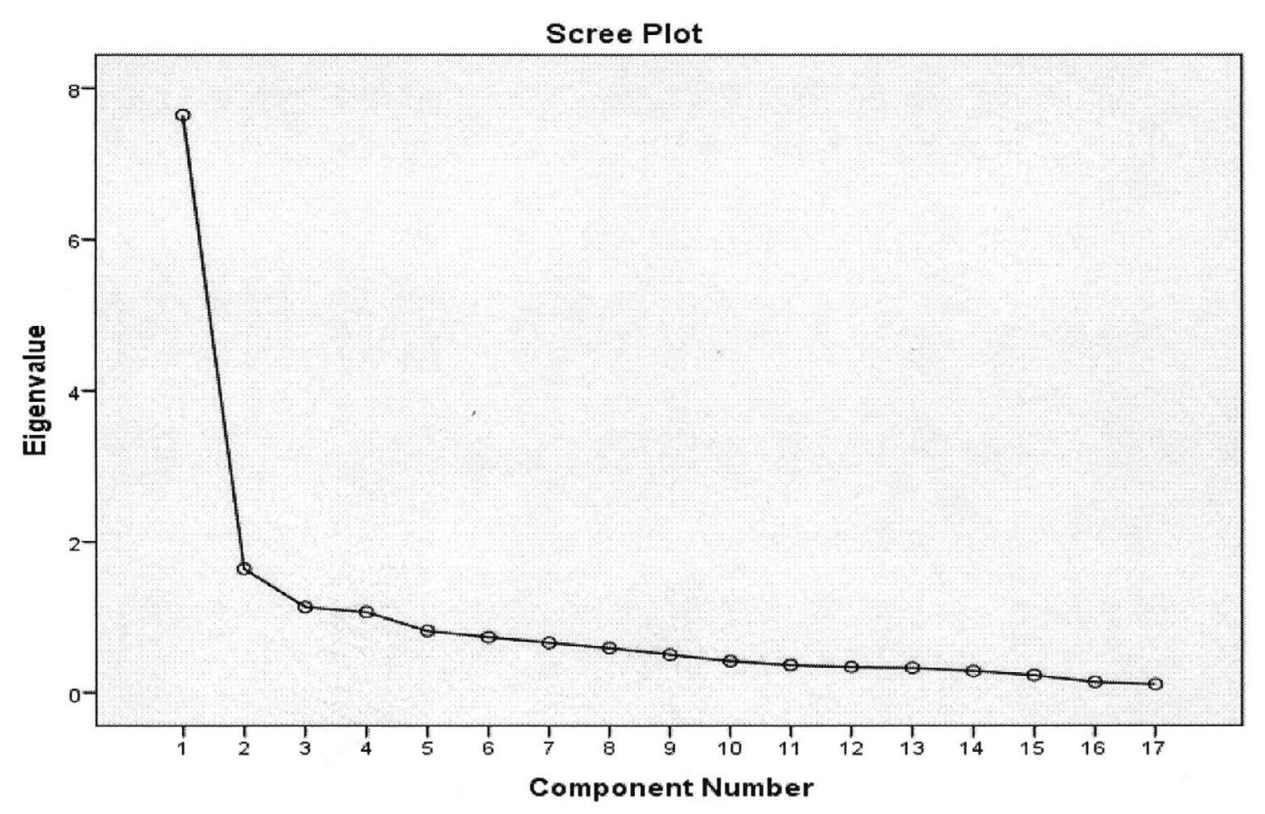

Figure 2: The Scree plot graph of the Spirituality and Spiritual Care Rating Scale

tor analysis as the samplesize of the study was large enough to support the analysis. The KMO value was within the range of between 0.8 and 0.9 indicating that the SSCRS was worthy for determining the factor analysis. Additionally, the items of the SSCRS were found to be statistically significant as the Barlett's test was 905.5 I I with a $p$-value $<0.000$. A scree plot of the eigenvalues indicated that four factors could be extracted from the data of SSCRS (Figure 2). The PCA indicated that the four factors had an eigenvalue higher than one (Table III). Therefore, the factor analysis from the varimax rotated test showed that the variances of the four factors were $25.1,22.0,1 \mathrm{I} .5$, and $8.8 \%$ respectively. The four factors all together explained $67.6 \%$ of the variance.

\section{Internal consistency reliability for SOTS}

\section{Internal consistency reliability of SSCRS}

The internal consistency reliability of the SSCRS demonstrated a reliable measurement with a Cronbach's $(\alpha=0.764)$. The reliability coefficients of the SSCRS's factors ranged from $\alpha=0.270$ to $\alpha=0.886$. Factor 4 (Personalised Care) of this measurement obtained a lower reliability coefficient of $\alpha=0.270$.

\section{Exploratory Factor Analysis: SSCRS}

The SSCRS analysis showed that the KMO accounted for 0.883; which indicated that the scale was creditable for anexploratory fac-
The internal consistency reliability of the SOTS was found to be $\alpha=0.868$ which demonstrated a good reliability. The reliabilities of the factors ranged from $\alpha=0.565$ to $\alpha=0.94$ I. Factor I (Inclusion of spirituality in the OTPF) of the SOTS scored higher than the other factors in the scale with a Cronbach alpha of $(\alpha=0.94 \mathrm{I})$.

\section{Exploratory Factor Analysis: SOTS}

From the analysis of the SOTS, it was found that the KMO was 0.808 , which indicated that the SOTS was commendable for the exploratory factor analysis as the KMO was within range of 0.8 and 0.9.The Barlett's test of the SOTS was 1372.997 indicating that

Table III: Principal components and associated variable

\begin{tabular}{|c|c|c|c|}
\hline Factor & No & Statement & $\begin{array}{l}\text { Factor } \\
\text { Loading }\end{array}$ \\
\hline \multirow{6}{*}{ Spirituality } & 6 & I believe spirituality is about finding meaning in the good and based on events of life & 0.809 \\
\hline & II & I believe spirituality is a unifying force which enables one to be at peace with oneself and the world & 0.718 \\
\hline & 9 & I believe spirituality is about having a sense of hope in life & 0.705 \\
\hline & 3 & I believe spirituality is concern with a need to forgive and a need to be forgiven. & 0.692 \\
\hline & 8 & I believe occupational therapists can provide spiritual care by enabling a patient to find meaning and purpose in their illness & 0.681 \\
\hline & 13 & $\begin{array}{l}\text { I believe occupational therapists can provide spiritual care by listening to and allowing patients' time to discuss and } \\
\text { explore their fears, anxieties and troubles }\end{array}$ & 0.660 \\
\hline \multirow{8}{*}{$\begin{array}{l}\text { Spiritual } \\
\text { Care }\end{array}$} & 15 & I believe spirituality involves personal friendship and relationships. & 0.796 \\
\hline & 7 & $\begin{array}{l}\text { I believe occupational therapists can provide spiritual care by spending time with a patient giving support and reassur- } \\
\text { ance especially in time of need. }\end{array}$ & 0.711 \\
\hline & 2 & I believe occupational therapist can provide spiritual care by showing kindness, concern and cheerfulness when giving care & 0.672 \\
\hline & 16 & I believe spirituality does not apply to Atheists or Agonists & -0.575 \\
\hline & 17 & I believe spirituality include people's morals. & 0.573 \\
\hline & 14 & $\begin{array}{l}\text { I believe occupational therapists can provide spiritual care by having respect of privacy, dignity and religious and cul- } \\
\text { tural beliefs of patient. }\end{array}$ & 0.549 \\
\hline & 10 & I believe spirituality is to do with the way one conducts one's life here and now & 0.458 \\
\hline & 1 & $\begin{array}{l}\text { I believe occupational therapist can provide spiritual care by arranging a visit by the hospital Chaplain or the patient's } \\
\text { own religious leader if requested }\end{array}$ & 0.428 \\
\hline \multirow{3}{*}{ Religiosity } & 16 & Does not apply to Atheist or Agonists & 0.522 \\
\hline & 12 & I believe spirituality does not include areas such as art, creativity and self-expression & 0.802 \\
\hline & 4 & I believe spirituality involves only going to Church/Place of Worship & 0.741 \\
\hline $\begin{array}{l}\text { Person- } \\
\text { alised Care }\end{array}$ & 5 & I believe spirituality is not concerned with a belief and faith in a God or Supreme being & -0.866 \\
\hline
\end{tabular}




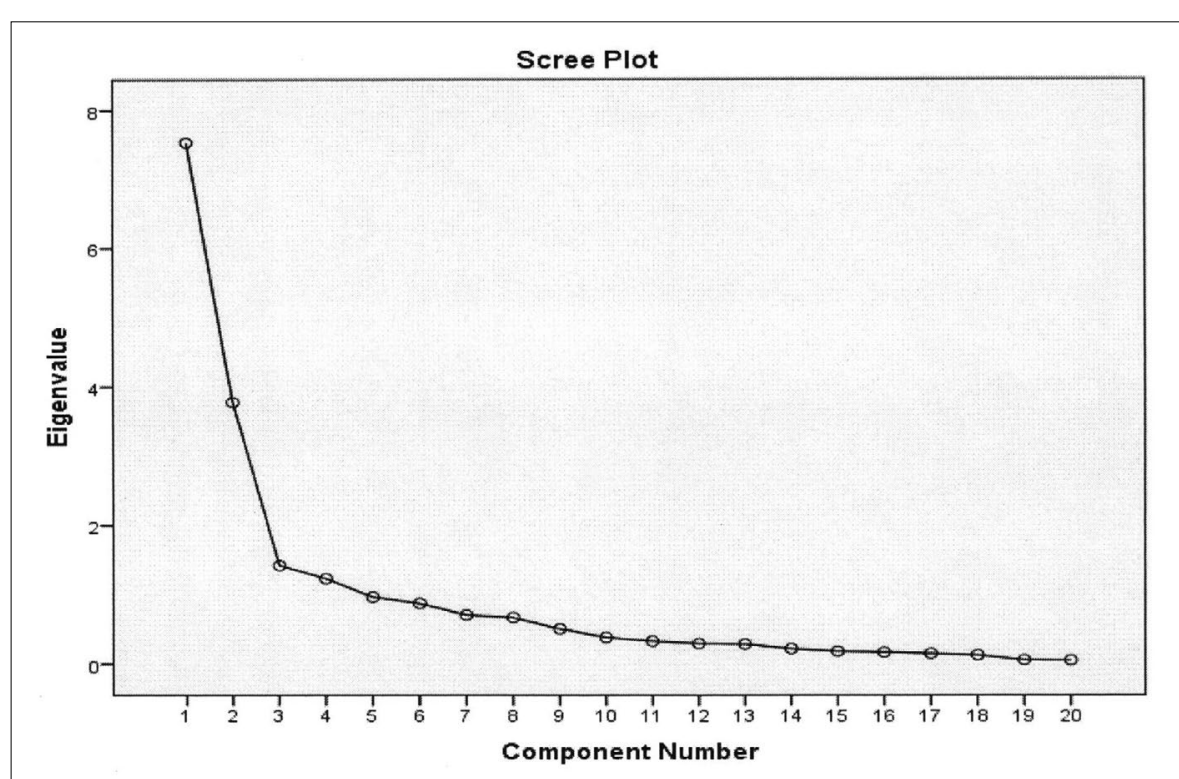

Figure 3: The Scree plot graph of the Spirituality in Occupational Therapy Scale

there was a correlation among the items of the SOTS with statistical significance at a level of $p$-value of $<0.000$. Hence, a scree plot of the eigenvalues indicated that four factors could be extracted from the data of the SOTS (Figure 3). The PCA revealed that the four factors had an eigenvalue greater than one (Table IV). Therefore, the factor analysis from the varimax rotated test indicated that the variances of the factors were $27.3,18.1,17.3$, and $7 \%$ respectively. In total, the four-factor solution explained $69.8 \%$ shared variance of the twenty items.

\section{Table IV: Principal components and associate variable}

\begin{tabular}{|c|c|c|c|}
\hline Factor & No & Statement & $\begin{array}{l}\text { Factor } \\
\text { Loading }\end{array}$ \\
\hline \multirow{7}{*}{$\begin{array}{l}\text { Inclusion of } \\
\text { spirituality } \\
\text { in OTPF }\end{array}$} & 17 & Spirituality helps clients define who they are & 0.899 \\
\hline & 20 & $\begin{array}{l}\text { It is appropriate to include spirituality as a client factor in the Occupational Therapy Practice Frame- } \\
\text { work } 2 \text { nd Ed }\end{array}$ & 0.869 \\
\hline & 18 & Spirituality is an integral part of the human experience & 0.826 \\
\hline & 14 & I believe that treating my client's spiritual need has a direct effect on my client's quality of life. & 0.796 \\
\hline & 19 & I am familiar with the Occupational Therapy Practice Framework 2nd Ed & 0.774 \\
\hline & 16 & Spirituality helps clients define their therapeutic goals & 0.725 \\
\hline & 2 & $\begin{array}{l}\text { My treatment sessions would be enhanced if I had more education about how to address my clients' } \\
\text { spiritual needs. }\end{array}$ & 0.577 \\
\hline \multirow{7}{*}{$\begin{array}{l}\text { Spirituality } \\
\text { in practice }\end{array}$} & 8 & My experience as an OT practitioner has prepared me to adequately address my client's spiritual needs. & 0.877 \\
\hline & 15 & I treat my client's spiritual needs. & 0.806 \\
\hline & II & I use spiritual assessments to evaluate my client's spiritual needs. & 0.751 \\
\hline & I & My formal education has adequately prepared me to address my clients' spiritual needs. & 0.679 \\
\hline & 9 & I feel comfortable addressing spirituality with my clients. & 0.668 \\
\hline & 12 & I am aware of various assessments that address spiritual needs of my clients. & 0.628 \\
\hline & 13 & I am confident addressing the spiritual needs of my clients when their beliefs are similar to my own. & 0.440 \\
\hline \multirow{4}{*}{$\begin{array}{l}\text { Need for } \\
\text { future } \\
\text { education }\end{array}$} & 10 & It is my responsibility to address my client's spiritual needs. & 0.736 \\
\hline & 6 & Spirituality should be addressed by occupational therapists. & 0.708 \\
\hline & 3 & I would like to pursue further education about how to address my clients' spiritual needs. & 0.700 \\
\hline & 5 & $\begin{array}{l}\text { I would benefit from attending an educational workshop about addressing and evaluating the spiri- } \\
\text { tual needs of my clients. }\end{array}$ & 0.680 \\
\hline \multirow{2}{*}{$\begin{array}{l}\text { Clients' } \\
\text { Spiritual } \\
\text { needs }\end{array}$} & 7 & It is the client's responsibility to inform the occupational therapist of their spiritual needs. & 0.851 \\
\hline & 4 & I make an effort to find more information on spirituality as it relates to OT practice. & 0.674 \\
\hline
\end{tabular}

\section{DISCUSSION}

This appears to be the first study to assess the internal consistency component of the reliability of the research instruments and carry out a factor analysis of the perceptions and attitudes of undergraduate occupational therapy students regarding spirituality and spiritual care. Generally, the results of the study, with regard to the internal consistency component of reliability testing of the three research instruments, indicated that they were highly reliable to measure perceptions and attitudes about spirituality and spiritual care. The findings revealed that the component of reliability of the SCGS was Cronbach's alpha of $(\alpha=0.94)$ which was very close to the Cronbach's alpha of 0.96 in the study by Tiew and Creedy ${ }^{20}$. The reliability results of the SSCRS in the current study showed Cronbach's alpha as 0.76 , and were consistent with the study of Martins, Calderia and Pimentel ${ }^{9}$ which reported a Cronbach's alpha of 0.76 . The results of the present study were higher than that of a study by McSherry et al. ${ }^{21}$ which reported Cronbach's alpha of 0.64 . The internal consistency component of reliability of the SOTS in the current study was 0.86 , albeit, there was no reliability test performed for the SOTS in Morris et al.'s study ${ }^{22}$. It seems possible that these results are due to the fact that the participants perceived spirituality as a factor that influences clients' quality of life and occupational performance. This study provides realistic evidence to support the validity and reliability of the SOTS since it measures what it is supposed to measure regarding spirituality and spiritual care. 
The findings indicated that the values of the Cronbach's alpha of the research instruments were high and this could suggest that the students who participated in the study had some knowledge about the importance of spirituality in occupational therapy. Therefore, this indicates that the content of the instruments was explicit and students could understand what was expected from them. Thus, these instruments may be used with other occupational therapy students in other institution of higher learning within the context of South Africa.

The current study planned to use one of the multivariate statistical methods such as factor analysis which is perceived as a complex methodology. Therefore, Beavers et al. ' provided various preconditions that researchers should consider prior to carrying out factor analysis including sample size, component analysis and common factor analysis as well as the need to rotate the initial factor pattern. These conditions assisted the researchers to interpret and provide meaningful solutions in order to make decisions about performing factor analysis. Therefore, the results of the present study met the preconditions suggested by Beavers et al. '. This study similarly achieved the assumptions suggested in Leech et al. ${ }^{25}$ that the $\mathrm{KMO}$ should be above 0.70 in order to interpret the findings. Hence, all the research instruments were within the range of 0.80 and 0.89 which Beavers et al. ' indicated was a meritorious degree of common variance. This suggested that factor analysis was an appropriate method for use in the study. For instance, the present total variances explained that in all of the variables together the scales accounted for these score: SCGS five factors explaining $59.1 \%$ of the total variability; SSCRS four factors explaining $67.6 \%$ and SOTS four factors explaining $69.8 \%$. These variances of the SCGS, SSCRS and SOTS were all higher than $50 \%$ which indicated that the factors extracted were acceptable.

The results of this study indicate that the internal consistency of the Attributes of Spiritual Care (Factor I) in SCGS was higher than that of a study by Tiew and Creedy ${ }^{20}$ with $\alpha=0.93$ versus $\alpha=$ 0.90 respectively. Therefore, this provides evidence with respect to spiritual care as the participants might have valued the importance of empathy, trusting relationship and self-awareness of own spirituality. The current findings add substantially to our understanding of the importance of spirituality and spiritual care in occupational therapy education. However, in this factor item 27 (Spiritual care should take into account of what patients think about spirituality) had a higher coefficient of 0.72 , but in the study by Tiew and Creedy ${ }^{20}$ scored 0.618 . The present study confirms previous findings and contributes additional evidence that suggests that client-centred and holistic approaches should be a priority regarding spirituality. This could mean that clients' autonomy should be respected at all times when considering spirituality. Thus, students should be educated that they may not impose their beliefs systems on their clients. This study has been unable to demonstrate similar factor loadings in comparison with the previous study ${ }^{20}$. For instance, only seven out of nineteen items were loaded with the same factor loadings when compared with the study by Tiew and Creed ${ }^{20}$. In Factor 2: Spiritual Perspective, ten items were loaded, however, four of the items were similar to the previous study. This factor had a higher loading in item 7 compared to the study by Tiew and Creedy ${ }^{20}(\alpha$ $=0.689$ versus $\alpha=0.627$ ). Regarding Factor 3 (Defining Spiritual Care), in this study, four items were loaded but they were completely different from those in the Tiew and Creedy ${ }^{20}$ study. The differences in the factor loading for this factor could be explained by understanding the contextual factor of the respondents such as racial beliefs, culture, and ethnicity. These support Janse van Rensburg et al. ${ }^{7}$ who reported that the South African population is multi-cultural, multi-religious and spiritually diversified. However, some of these contextual factors might make addressing spirituality challenging for the students. Factor 4 only had two items loaded which were different from the original study conducted by Tiew and Creedy ${ }^{20}$ which had six items.

The present findings of the study regarding factor analysis for SSCRS contrast with some of the factor loadings of previous research by McSherry et al. ${ }^{21}$. In SSCRS, Factor I (Spirituality), items in this factor were related to how the participants perceive spirituality. The issues included finding meaning in the good life, sense of hope in life, listening to patients and allowing patients' time to discuss. The present findings, however, makes several noteworthy contributions to occupational therapy education about the significance of spirituality in providing meaning and purpose. This is confirmed in the study by McSherry et al. ${ }^{21}$ which reported that life and existence were imperative in a holistic approach. Additionally, the findings of the present study are consistent with McSherry et al. ${ }^{21}$ concerning Factor 2 (Spiritual Care), indicating that occupational therapy students perceived kindness, and being cheerful as important elements of providing occupational therapy services. This corroborates with Rooyen' ${ }^{26}$ and Pentland and McColl's ${ }^{27}$ discussion that occupational therapy should be concerned with virtues of doing good, including care, compassion as well as kindness, and a humanistic approach. Factor 3 (Religiousity), in this factor loadings were completely different from the original study by McSherry et al. ${ }^{21}$. However, these loading differences may be explained by the diversity of occupational therapy students who participated in the study. The belief system of the students appears to be different from the previous study by McSherry et al. ${ }^{21}$, as in this study, it was found that students believed that spirituality includes morals, respect for privacy, dignity and religious and cultural beliefs of patients. Additionally, people's conduct of life was related to spirituality. This could mean that greater emphasis may be placed on teaching spirituality in order for all students to have debates about it. However, in Factor 4 (Personalised Care), this study had three variables loaded though they were different from McSherry et al.' $\mathrm{s}^{21}$ factor loadings.

This study provides realistic evidence to support SOTS as a tool to assess occupational therapy students' perceptions and attitudes regarding spirituality as an integral componentoftheir education. In SOTS, Factor I (Spirituality in the scope of practice) there were seven items loaded $(17,20,18,14,19,16,2)$. The factor loadings in this factor seemed to address important issues such as spirituality as a client factor, therapeutic goals, personal identity, human experience, quality of life and education. Additionally, this factor supports previous studies that reported that spirituality is unique to every individual ${ }^{8,21}$. The current findings add to a growing body of literature on spirituality and the OTPF. These findings also enhance our understanding of why spirituality was incorporated in the OTPF. This could be explained by the fact that spirituality was perceived as part of quality of life, self-awareness and assists clients to set their goals. For instance, the AOTA $^{6}$ included the spiritual dimension within the framework as an enabler to facilitate occupational performance. In Factor 2 (Spirituality in practice) there were seven variables loaded with highest scores which showed occupational therapy students' confidence about spirituality. However, these variables were more related to the role of spirituality in practice and professionalism. Thus, the factor name was changed based on the understanding of the loading. These variables include being confident in addressing spiritual needs, and awareness of assessments. The study has gone some way towards enhancing our understanding of spirituality as an integral part of human experience which plays an important role in practice. This is supported by McColl' $\mathrm{s}^{28}$ explanation that spirituality is the bridge to health and occupation.

Regarding, Factor 3 (Formal education and training in spirituality), there were four variables loaded around this factor $(10,6,3$, 5) which were concerned with aspects of education, responsibility and attentiveness to the needs of clients. The variables related to further education and workshops about spirituality obtained high scores. Importantly, the study's findings also demonstrate that there is, therefore, a definite need for greater emphasis to be placed on teaching undergraduate occupational therapy students about spirituality. Furthermore, this may need further research to develop guidelines for integrating spirituality in occupational therapy education. This also suggests that occupational therapists may need to have continuous professional development and workshops in 
relation to spirituality in order to understand clients' spiritual needs. These findings support the studies which reported that occupational therapy professionals and other healthcare professionals need to be aware of the clients' spiritual needs in order to refer the client to the relevant members of the interdisciplinary team ${ }^{7,15,29,30,31}$. Factor 4 (Clients' spiritual needs) had two variables related to spirituality which involve clients' and clinician responsibilities. These findings support the assertion of Hammel ${ }^{30}$, and Mthembu, Roman and Wegner $^{32}$ that client-centred practice should enhance collaborative partnerships between occupational therapists and clients to promote autonomy, choice and control, as well as respect for clients' abilities.

Finally, two important limitations need to be considered. Firstly, the participants might have wished to please the researcher and answered accordingly. Secondly, there was a low response rate and the study was conducted in one occupational therapy department. Therefore, the results of the study may not be generalised to other students from other institutions of higher learning. Hence, it is recommended that further research be undertaken in other institutions of higher learning with occupational therapy programmes.

\section{CONCLUSION}

This study assessed the internal consistency component of reliability of three research instruments and carried out a factor analysis of the perceptions and attitudes of undergraduate occupational therapy students regarding spirituality and spiritual care. All spirituality scales (SCGS, SSCRS and SOTS) were found to be reliable, though some of the factor loadings were different from the previous studies that used the scales. These instruments could be used as part of workshops and seminars to collect baseline information about clinicians and students' perceptions and attitudes towards spirituality. The factor analysis was performed to extract various factors related to spirituality and spiritual care in occupational therapy using the three measurements. An implication of these findings is the possibility that exposing occupational therapy students to spirituality and spiritual care could be useful for them to have insight into and be sensitive to, the clients' spiritual needs. Furthermore, the results of the present study suggest that these instruments may be used with other healthcare professionals as part of continuous professional development regarding spirituality. However, more research may be needed with other occupational therapy education programmes in South Africa for a larger, representative sample.

\section{ACKNOWLEDGEMENTS}

This work is based on the research supported in part by the National Research Foundation of South Africa - Unique Grant No. 93992. Any opinion, finding and conclusion or recommendation expressed in this material is that of the author(s) and the NRF does not accept any liability in this regard. We acknowledge Prof W. McSherry, Prof LH Tiew and Prof DN Morris for their permission to use their research instruments.

\section{REFERENCES}

I. Beavers AS, Lounsbury JW, Richards JK, Huck SW., Skolits GJ, Esquivel SL. Practical considerations for using exploratory factor analysis in educational research. Practical Assessment, Research \& Evaluation, 2013; 18(6): I-13.

2. Kayastha R, Murthy VK, Adhkary PR. Factor analysis and principal component analysis concerning to occupational stress among executive officers of Nepal. Universal Journal of Computational Mathematics, 2015; 3(I): I-7.

3. Venkaiah K, Braham GNV, Vijayaraghavan K. Application of factor analysis to identify patterns and use of factor scores to study their relationship with nutritional status of adult rural populations. Journal of Health Population Nutrition, 20 I I; 29(4): 327-338.

4. Johnston D., Mayers C. Spirituality: a review of how occupational therapists acknowledge, assess and meet spiritual needs. British Journal of Occupational Therapy, 2005; 68(9): 386-392.

5. Puchalski C, Vittillo R, Hull S, Reller R. Improving the spiritual dimen- sion of whole care: Reaching national and international consensus. Journal of Palliative Medicine, 20 I4; I7(6): 642-656.

6. American Occupational Therapy Association. Occupational therapy practice framework: Domain and process ( $3^{\text {rd }}$ ed.). American Journal of Occupational Therapy, 20 I4; 68(Suppl. I): SI-S48. http://dx.doi. org/I0.50I4/ajot.2014.682006

7. Janse van Rensburg ABR, Poggenpoel M, Szabo CP, Myburgh CPH. Referral and collaboration between South African psychiatrist and religious or spiritual advisers: Views from some psychiatrists. South African Journal of Psychiatry, 2014; 20(2): 40-45. DOI:I0.7196/ SAJP.533.

8. Mthembu TG, Ahmed F, Nkuna T, Yaca K. Occupational therapy students' perceptions of spirituality in training. Journal of Religion and Health, 20I4. [Under press].

9. Martins AR, Pinto S, Calderia S, Pimentel FL. Translation and adaptation of the spirituality and spiritual care rating scale in Portuguese palliative care nurses. Revista de EnfermagemReferência, 2015; Série IV - no. 4: 89-97.

10. Farrar JE., Otr L. Addressing Spirituality and Religious Life in Occupational Therapy Practice. Physical \& Occupational Therapy in Geriatrics, 200।; 18(4): 65-85.

II. Egan M, Swedersky J. Spirituality as experienced by occupational therapists in practice. American Journal of Occupational Therapy, 2003; 57: 525-533.

12. Capeheart-Meningall J. Role of spirituality and spiritual development in student life outside the classroom. New Directions For Teaching and Learning, 2005; 104: 31-35.

13. Thompson BE, MacNeil C. A phenomenological study exploring the meaning of a seminar on spirituality for occupational therapy students. The American Journal of Occupational Therapy, 2006; 60(5): $531-539$.

14. Csonto S. Occupational therapy students' consideration of clients' spirituality in practice placement education. British Journal of Occupational Therapy, 2009; 72(10):442-449.

15. Janse van Rensburg ABR, Szabo CP, Poggenpoel M, Myburgh C. Competence of medical students and residents in psychiatry regarding spirituality, at a South African School of Clinical medicine. International Journal in Medicine, 2013; 45: I75-188.

16. Hemphill B. Spiritual Assessments in Occupational Therapy, The Open Journal of Occupational Therapy, 2015; 3(3) http://dx.doi. org/10.15453/2168-6408.1159.

17. Deloney LA, Graham C], Erwin DO. Presenting cultural diversity and spirituality in First-year medical students. Academic Medicine, 2000; 75(5): 513.

18. Hage SM, Hopson A, Siegel M, Payton G, DeFanti E. Multicultural training in Spirituality: An Interdisciplinary Review. Counseling and Values, 2006; 50(3): 217-234.

19. Dalton JC. Exploring spirituality and culture in Adult and Higher education (Review). Journal of College Student Development, 44(6): 86I-863.

20. Tiew LH, Creedy DK. Development and preliminary validation of composite spiritual care-giving scale. International Journal of Nursing Studies, 2012; 49: 682-690.

2I. McSherry W, Draper P, Kendrick D. Construct validity of a rating scale designed to assess spirituality and spiritual care. International lournal of Nursing Studies, 2002; 39(7): 723-734.

22. Morris DN, Stecher J, Briggs-Peppler KM, Chittenden CM, Rubira J, Wismer L.K. Spirituality in Occupational Therapy: Do We Practice What We Teach? Journal of Religion and Health, 20 I2; doi: $10.1007 /$ sl 0943-012-9584-y.

23. Laher S. Using exploratory factor analysis in personality research: Best-practice recommendations. SA Journal of Industrial Psychology/SA TydskrifvirBedryfsielkunde, 2010. 36(I), Art. \#873, 7 pages. DOI: 10.4102/sajip.v36il.873.

24. Van Zyl CJJ, Taylor N. (20I2). Evaluating the MBTI@ Form M in a South African context. SA Journal of Industrial Psychology/SATydskrifvirBedryfsielkunde, 38(I), Art. \#977, I5 pages. http://dx.doi. org/10.4102/sajip.v38il.977.

25. Leech NL, Barrett KC, Morgan G. SPSS for intermediate statistics: Use and interpretation. (2nd Edition). Lawrence Erlbaum Associates, Publishers. Mahwa, New Jersey: London. 2005.

26. Royeen CB. Chaotic occupational therapy: Collective wisdom for a complex profession, 2003 Eleanor Clarke Slagle lecture. American 
Journal of Occupational Therapy, 2003; 57: 609-624.

27. Pentland W, McColl MA. Occupational integrity: Another perspective on "life balance". Canadian Journal of Occupational Therapy, 2008; 75(3): 135-138.

28. McColl MA. Models of spirituality, occupation and health, Chapter 8. In Spirituality and Occupational Therapy. (2 ${ }^{\text {nd }}$ Edition). McColl M.A. CAOT Publications ACE: Ottawa, 201 I.

29. De Jongh J, Hess-April L, Wegner, L. Curriculum transformation : A proposed route to reflect a political consciousness in occupational therapy education. South African Journal of Occupational Therapy, 20I2; 42(I): $16-20$.

30. Hammel KW. Using qualitative research to inform the client-centred evidence-based practice of occupational therapy. British Journal of Occupational Therapy, 200I; 64(5): 228-234.

3I. Balboni M, Bandini J, Mitchell C, Epstein-Peterson ZD, Amobi A, Cahill J, Enzinger AC, Peteet J, Balboni T. Religion, Spirituality, and the Hidden Curriculum: Medical Student and Faculty Reflections. Journal of Pain and Symptom Management, 2015; doi: 10.1016/j. jpainsymman.2015.04.020.

32. Mthembu TG, Roman NV, Wegner L. A cross-sectional descriptive study of occupational therapy students' perceptions and attitudes towards spiritual care in occupational therapy education. Journal of Religion and Health, 2015; DOII0.1007/S10943-0I5-0123-3. 